International Mathematical Forum, 2, 2007, no. 40, 1985 - 1988

\title{
Ranking of Extreme and Non-Extreme Efficient DMUs
}

\author{
G. Tohidi ${ }^{a, 1}$, S. Razavyan ${ }^{b}$ and K. Ranjbar ${ }^{a}$ \\ ${ }^{a}$ Department of Mathematics \\ Islamic Azad University \\ Tehran-Center Branch, Tehran-Iran \\ ${ }^{b}$ Department of Mathematics \\ Islamic Azad University \\ Tehran-South Branch, Tehran-Iran
}

\begin{abstract}
There are several methods for ranking of the extreme efficient DMUs. The non-extreme efficient DMUs cannot rank by these methods. In this paper, we propos a method for ranking all efficient DMUs (extreme and non-extreme efficient DMUs) by using reference DMUs.
\end{abstract}

Keywords: Data Envelopment Analysis, Ranking, Efficiency, and reference set

\section{Introduction}

Data Envelopment Analysis (DEA), Charnes et. al [3], is a mathematical programming technique for identifying efficient frontiers for peer Decision Making Units (DMUs). In most models of DEA, the best performers have efficiency score unity, and, from experience, we know that usually there are plural DMUs, which have this "efficient status". To discriminate between these efficient DMUs is an interesting research subject. Several authors have proposed methods for ranking the best performers. See Andersen and Petersen (AP)[1], Seiford and Zhu [6], Zhu [7] and Mehrabian, Alirezai and Jahanshahloo (MAJ) [5] and Jahanshahloo et al. [4] among others.

All these ranking methods have been applied for ranking only extreme efficient DMUs. In this paper, we use the convex combination of extreme efficient DMUs rank, which are references DMUs, for ranking non-extreme

\footnotetext{
${ }^{1}$ Corresponding author, Tel: (+98)-21-44811232, P. O. Box 14515-459, Email: ghatohidi@yahoo.com
} 
efficient DMUs. We assume that there is $n$ DMUs to be evaluated, indexed by $j=1, \ldots, n$ and $Y_{j}=\left(y_{1 j}, \ldots, y_{s j}\right)$ each DMU is assumed to produce $\mathrm{s}$ different outputs from $m$ different inputs. Let the observed input and output vectors of $\mathrm{DMU}_{j}$ be $X_{j}=\left(x_{1 j}, \ldots, x_{m j}\right)$ and respectively, that all components of vectors $X_{j}$ and $Y_{j}$ for all DMUs are non-negative and each DMU has at least one strictly positive input and output. To obtain efficiency of DMUs we use the CCR [5], which is as follows:

$$
\begin{aligned}
& \theta_{C C R}^{*}=\operatorname{Min} \theta_{C C R} \\
& \text { s.t. } \quad \sum_{j=1}^{n} \lambda_{j} x_{i j} \leq \theta_{o} x_{i o}, \quad i=1, \cdots, m \\
& \sum_{j=1}^{n} \lambda_{j} y_{r j} \geq y_{r o}, \quad r=1, \cdots, s \\
& \lambda_{j} \geq 0, \quad j=1, \cdots, n .
\end{aligned}
$$

Assume that the $\mathrm{DMU}_{o}$ is extreme efficient. To obtain the ranking score of $\mathrm{DMU}_{o}$, consider the model $\mathrm{AP},[2]$, as follows:

$$
\begin{aligned}
& \theta_{A P}^{*}=\operatorname{Min} \theta_{A P} \\
& \text { s.t. } \quad \sum_{j=1, j \neq o}^{n} \lambda_{j} x_{i j} \leq \theta_{o} x_{i o}, \quad i=1, \cdots, m \\
& \sum_{j=1, j \neq o}^{n} \lambda_{j} y_{r j} \geq y_{r o}, \quad r=1, \cdots, s \\
& \lambda_{j} \geq 0, \quad j=1, \cdots, n, j \neq o .
\end{aligned}
$$

The structure of the paper is as follows. In section 2 we propose a method for ranking non-efficient DMUs. In section 3, a numerical example is considered which illustrates the presented method. Section 4 gives our conclusive remarks.

\section{Ranking of Non-Extreme Efficient DMUs}

The previous ranking methods are applied for ranking only extreme efficient DMUs. In this paper, we use the convex combination of extreme efficient DMUs rank, which are references DMUs, for ranking non-extreme efficient DMUs. We know each non-extreme efficient DMU has at least two extreme efficient references. So, suppose that the $\mathrm{DMU}_{o}$ is non-extreme efficient and $\Lambda_{o}=o_{1}, \ldots, o_{p}$ be the set of index DMUs which are references DMUs for $\mathrm{DMU}_{o}$.

Theorem 1: Each non-extreme efficient DMU can be represented by the convex combination of its extreme efficient reference set DMUs.

Proof: The proof is similar to representation theorem in [2]. 
Since $\mathrm{DMU}_{o}$ and its reference set DMUs are almost similar. So their performance and rank are nearly similar. Therefore from theorem 1 and above discussion, we define the rank of non-extreme DMUs based on the density of reference set DMUs in CCR model as definition 1.

Definition 1: Assume that $\mathrm{DMU}_{o}$ is non-extreme efficient, then its rank $\left(\mathrm{R}_{o}\right)$ is defined as, $R_{o}=\sum_{o_{j} \in \Lambda} \lambda_{o_{j}}^{*} R_{o_{j}}^{*}$, where for $o_{j} \in \Lambda_{o}, R_{o_{j}}$ is the rank of $o_{j}-t h$ DMU and $\lambda_{o_{j}}^{*}$ is its intensity in CCR model and can be obtained from optimal solution of model (1) when $\mathrm{DMU}_{o}$ is evaluated.

\section{Example}

Consider 11 DMUs with 2 inputs and 1 output. The data of these DMUs have been reported in Table 1 .

\begin{tabular}{|l|ccccccccccc|}
\hline DMUs & $\mathrm{A}$ & $\mathrm{B}$ & $\mathrm{C}$ & $\mathrm{D}$ & $\mathrm{E}$ & $\mathrm{F}$ & $\mathrm{G}$ & $\mathrm{H}$ & $\mathrm{I}$ & $\mathrm{L}$ & $\mathrm{M}$ \\
\hline Input1 & 1 & 2 & 4 & 1.5 & 1.8 & 1.25 & 3 & 4 & 5 & 3 & 5 \\
Input2 & 4 & 2 & 1 & 3 & 2.4 & 3.5 & 1.5 & 2 & 3 & 4 & 5 \\
Output & 1 & 1 & 1 & 1 & 1 & 1 & 1 & 1 & 1 & 1 & 1 \\
\hline
\end{tabular}

Table 1: The values of inputs and outputs

By CCR model DMUs D, E, F and G are non-extreme efficient and DMUs $\mathrm{A}, \mathrm{B}$ and $\mathrm{C}$ are extreme efficient. By using formula $R_{o}=\sum_{o_{j}} \lambda_{j_{o}}^{*} R_{j_{o}}$ the rank of on-extreme efficient DMUs have been reported in row 5 of table 2 .

\begin{tabular}{|c|c|c|c|c|c|c|c|}
\hline DMUo & $\mathrm{A}$ & $\mathrm{B}$ & $\mathrm{C}$ & $\mathrm{D}$ & $\mathrm{E}$ & $\mathrm{F}$ & $\mathrm{G}$ \\
\hline$\theta_{C C R}^{*}$ & 1 & 1 & 1 & 1 & 1 & 1 & 1 \\
\hline$\theta_{A P}^{*}$ & 1.25 & 1.0714 & 1.4999 & 1 & 1 & 1 & 1 \\
\hline$\Lambda_{o}$ & $\{\mathrm{~A}\}$ & $\{\mathrm{B}\}$ & $\{\mathrm{C}\}$ & $\{\mathrm{A}, \mathrm{B}\}$ & $\{\mathrm{A}, \mathrm{B}\}$ & $\{\mathrm{A}, \mathrm{B}\}$ & $\{\mathrm{B}, \mathrm{C}\}$ \\
\hline$R_{o}$ & 1.25 & 1.0714 & 1.4999 & 1.1607 & 1.1071 & 1.2053 & 1.2857 \\
\hline$\lambda_{j_{o}}^{*}, o_{j} \in \Lambda$ & $\lambda_{A}^{*}=1$ & $\lambda_{B}^{*}=1$ & $\lambda_{C}^{*}=1$ & $\lambda_{A}^{*}=0.5$, & $\lambda_{A}^{*}=0.2$, & $\lambda_{A}^{*}=0.75$, & $\lambda_{B}^{*}=0.5$, \\
& & & & $\lambda_{B}^{*}=0.5$ & $\lambda_{B}^{*}=0.8$ & $\lambda_{B}^{*}=0.25$ & $\lambda_{C}^{*}=0.5$ \\
\hline
\end{tabular}

Table 2: CCR efficiency, reference set, and the ranks

In Table 2, the numbers of the rows 2 and 3 show the efficiency and rank of efficient DMUs, respectively. In this Table rows 4 and 6 show reference set and their density, respectively.

\section{Conclusion}

In this paper, we proposed a ranking method for ranking extreme and nonextreme efficient DMUs based on the density of reference set DMUs in CCR model. So, this method is able to rank all efficient DMUs with constraint and variable returns to scale. It seems that ranking by this approach is more precise than other methods. 


\section{References}

[1] Andersen, P., Petersen, N.C, 1993, A procedure for ranking efficient units in data envelopment analysis, Management Science 39(10), 1261-1294.

[2] Charnes, A., W.W. Cooper, E. Rhodes, 1978, Measuring the efficiency of decision making units, European Journal of Operational Research 2, 429-444.

[3] Bazaraa,M.S., Hanif D. Sherali, C.M. Shertty, 1993, linear programming, and network flow, second Edition.

[4] Jahanshahloo, G.R., F. Hosseinzadeh Lotfi, N.Shoja, G.Tohidi, S.Razavyan, 2004, Ranking using 11-norm in data envelopment analysis, Applied Mathematics and Computation, 153, 215-224.

[5] Mehrabian, S., M. R. Alirezaee, G. R. Jahanshahloo 1999, A complete efficiency ranking of decision making units in data envelopment analysis, Computational Optimization and Applications, 14, 261-266.

[6] Seiford, L.M. and J. Zhu 1999, Infeasibility of super efficiency data envelopment analysis models, INFOR 37(2), 174-187.

[7] Zhu, J., 2001, "Super-efficiency and DEA sensitivity analysis", European Journal of Operational Research, 129, 443-455. 